\title{
Aspectos da cultura de consumo de álcool dos grupos escravizados
}

\section{Aspects of the alcohol consumption culture of enslaved groups}

Lucas Endrigo Brunozi Avelar ${ }^{1}$

No século XVIII a ideologia religiosa associava a ingestão de álcool pelos escravizados com a fonte dos pecados e no século XIX com a origem de males morais. Exemplo desta ideologia aparece quando, ao descrever as senzalas que observou, o viajante Ribeyrolles refere-se a elas como sendo "antros, onde reinam às vezes as distrações e prazeres bestiais da embriaguez, em que jamais se fala do passado, porque é a dor, nem do futuro porque está cerrado". A senzala então seria o espaço dominado pelo prazer bestial da embriaguez escrava, por sua vez, momento de negação completa ("jamais") do trabalho de memória marcado pelo sofrimento e negação completa do planejamento do porvir. Ademais, o consumo de álcool parecia apenas acontecer em excesso, como se não houvesse uso regulado e socialmente aceito entre os grupos escravizados.

Estudando a "macumba paulista", Roger Bastide encontra relato de que naquele ritual faziam "um feitiço' diante da imagem de Cristo, ao pé do qual puseram pinga e mandioca". Câmara Cascudo informa que a aguardente penetrou o cerimonial religioso e se integrou ao "patrimônio oblacional africano". Uma série de outras referências dão notícia da presença do álcool destilado presente nas experiências religiosas dos grupos escravizados. Nas festividades do cachambu e do jongo, por exemplo, a pinga é usada para molhar o couro dos tambores e afiná-los na fogueira, não apenas para ingestão. Por sua vez, ao estudar a vida cotidiana dos escravizados no Rio de Janeiro do século XIX, Mary Karash acrescentou outras razões do lugar da cachaça entre os africanos e seus descendentes: baixo preço, gênero básico da dieta, complemento alimentar (carência de alimentos nutritivos), socialmente aceitável entre os próprios escravizados e provoca embriaguez.

Tomando como horizonte conceitual as noções de gramática profunda (Mintz e Price) e memória subterrânea (Michael Pollak), pretendo nesta apresentação expor os resultados parciais do significado do consumo do álcool destilado durante a escravidão brasileira do período imperial, com destaque para a dimensão religiosa e embriagante da ingestão alcoólica. A proposta é fazer a crítica desta ideologia racista da embriaguez escrava identificando traços de uma cultura etílica afro-orientada, forjada no Sudeste escravista e que ainda guarda reminiscências nas práticas contemporâneas. Deste modo pretendemos investigar em que medida esta cultura de consumo alcoólico foi elemento de resistência ao cativeiro.

Palavras-chave: drogas; memória; escravidão; resistência.

Keywords: drugs; memory; slavery; resistance.

1 Doutorando em História Social na Universidade de São Paulo, professor efetivo da Universidade Estadual de Roraima, pesquisador do Laboratório de Estudos Históricos das Drogas e da Alimentação (LEHDA-USP). 